Check for updates

Cite this: RSC Adv., 2018, 8, 10314

Received 13th February 2018

Accepted 5th March 2018

DOI: $10.1039 / \mathrm{c} 8 \mathrm{ra01397g}$

rsc.li/rsc-advances

\section{Friedel-Crafts alkylation reaction with fluorinated alcohols as hydrogen-bond donors and solvents $\dagger$}

\author{
Ren-Jin Tang, Thierry Milcent and Benoit Crousse (D)*
}

\begin{abstract}
An effective and clean FC alkylation of indoles and electron-rich arenes with $\beta$-nitroalkenes in HFIP was reported. The desired products are formed rapidly in excellent yields under mild conditions without the need for any additional catalysts or reagents. Further, this methodology can be applied to one-pot synthesis of biologically active tryptamine derivatives.
\end{abstract}

Friedel-Crafts (FC) alkylation is one of the most important methods for $\mathrm{C}-\mathrm{C}$ bond formation in organic chemistry. ${ }^{1}$ The $\mathrm{FC}$ alkylation between indoles and $\beta$-nitroalkenes is of particular interest due to the versatility by which the nitro group can be transformed into other functional groups. ${ }^{2}$ Numerous researchers have developed new conditions and effective catalysts in the past decades. ${ }^{3}$ Among them, H-bond donor (HBD) catalysts have become a focus of an increasing amount of research. ${ }^{4}$ Significant advances have been made in the area of homogeneous HBD catalysts by using urea or thiourea, ${ }^{4 a}{ }^{2-}$ aminopyridinium ions ${ }^{4 b}$ boronate ureas, ${ }^{4 e}$ and silanediol. ${ }^{4 d, 4 f}$ However, the strong hydrogen-bonding nature of the HBD catalysts drives a detrimental self-association or aggregation, thus reducing or enhancing catalytic activity. ${ }^{5}$

Trifluoroethanol (TFE) and hexafluoro-2-propanol (HFIP), exhibit unique features in organic synthesis. Indeed, the presence of the strong electron-withdrawing trifluoromethyl group influences several key parameters: ionizing power, Brønsted

(a) HFIP-promoted FC benzylations (Paquin, Khaled)

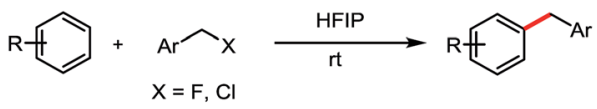

(b) HFIP-promoted FC acylations (Jeffrey Aube)

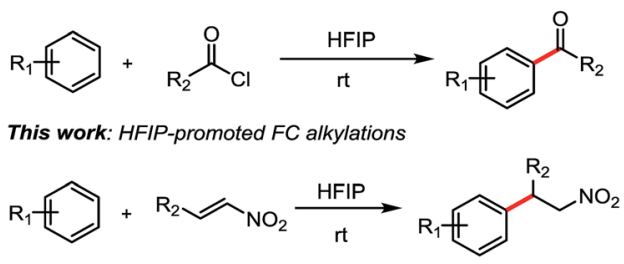

Scheme 1 Examples of FC alkylation promoted by HFIP.

Faculty of Pharmacy, UMR 8076, BioCIS, Univ. Paris-Sud, CNRS, Université Paris-Saclay, 92290, Châtenay-Malabry, France. E-mail: benoit.crousse@u-psud.fr

$\dagger$ Electronic supplementary information (ESI) available. See DOI: 10.1039/c8ra01397g acidity, and hydrogen-bond donation HBD (or H-bond acidity) are increased, whereas nucleophilicity and hydrogen-bond acceptance HBA (or H-bond basicity) are significantly depleted. ${ }^{6}$ Furthermore, the HBD was strongly connected to the conformation along the $\mathrm{C}-\mathrm{O}$ bond. Moreover, it was suggested that aggregation of HFIP as dimers or trimers could also enhance this property. ${ }^{7}$ Few FC alkylations have been studied solely in HFIP in last years. In 2010, Qu and co-workers described the intra- and intermolecular FC alkylations of electron-rich arenes with epoxides promoted by fluorinated alcohols. ${ }^{8}$ Recently, FC alkylations of arenes with benzyl halides in HFIP have been developed by Paquin et al. ${ }^{9}$ and Khaled et al. (Scheme 1a). More recently, HFIP promoting intramolecular and intermolecular Friedel-Crafts acylation have been reported by Jeffrey Aube and co-workers (Scheme 1b). ${ }^{10}$

Table 1 Optimization of conditions for the FC alkylation ${ }^{a}$

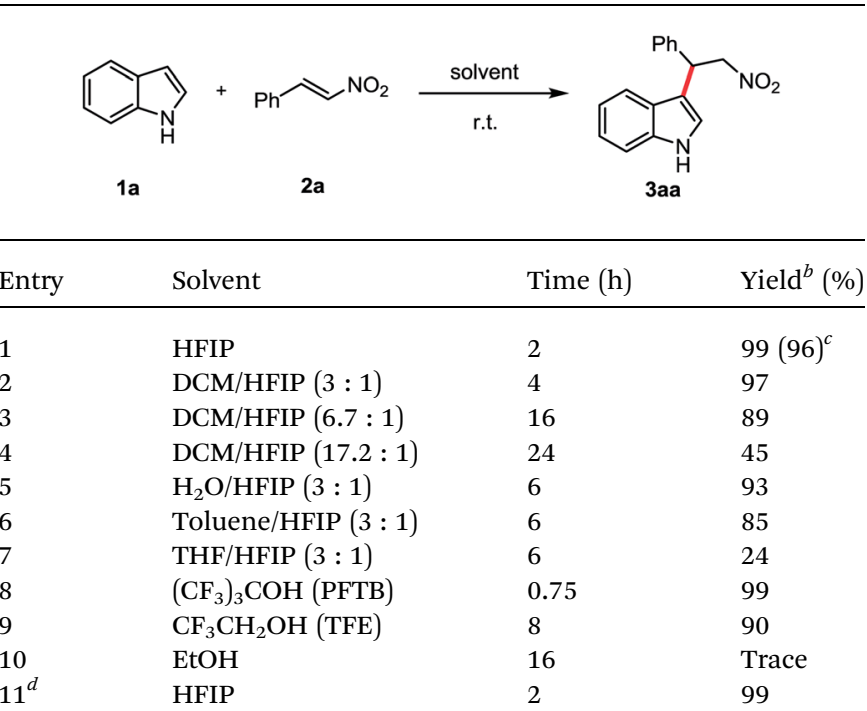

${ }^{a}$ Conditions: $1 \mathrm{a}(0.6 \mathrm{mmol}, 1.2$ equiv. $)$ and $\mathbf{2 a}(0.5 \mathrm{mmol})$ was dissolved in solvent $(0.25 \mathrm{M})$ and stirred at r.t. for a specified period unless otherwise noted. ${ }^{b}$ NMR yields using mesitylene as internal standard. ${ }^{c}$ Isolated yield in parentheses. ${ }^{d}$ The reaction was performed in the dark. 
In our interest for the use of fluorous medium in organic synthesis, ${ }^{\mathbf{1 1}}$ and in the pursuit of more efficient catalytic systems, we found that fluorinated alcohols promoted the FC alkylation between indoles and $\beta$-nitroalkenes.

The FC alkylation between indole (1a) and $\beta$-nitroalkene (2a) was used as model system to optimize the reaction conditions (Table 1). We first examined the reaction in pure HFIP solvent and the reaction mixture was stirred at r.t. for $2 \mathrm{~h}$. The product 3aa was isolated in $96 \%$ yield (entry 1). When HFIP was used as additive with other solvents (entries 2-7), good to moderate yields of 3aa were obtained. In DCM, the addition of HFIP from 2.0 to 9.5 equiv. (entries 4-6) decreased product yield and reaction rate. Good results were obtained when added 9.5 equiv. HFIP in water and toluene (entries 5 and 6). With THF the reaction was completely unfavourable (entry 7), probably because of the

Table 2 Scope of FC alkylation between indoles and $\beta$-nitroalkenes ${ }^{a}$
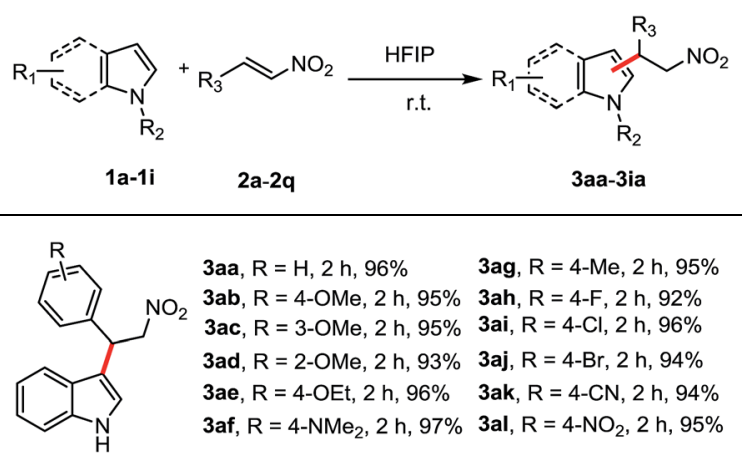<smiles>CCCCc1c[nH]c2ccccc12</smiles>

3am, 8 h, 90\%<smiles>O=[N+]([O-])CC(c1cccs1)c1c[nH]c2ccccc12</smiles>

3ap, 2 h, $92 \%$<smiles>[R]c1[nH]c2ccccc2c1C(C[N+](=O)[O-])c1ccccc1</smiles>

3ca, $R=M e, 2$ h, $95 \%$ $3 \mathrm{da},{ }^{b} \mathrm{R}=\mathrm{Ph}, 4 \mathrm{~h}, 85 \%$

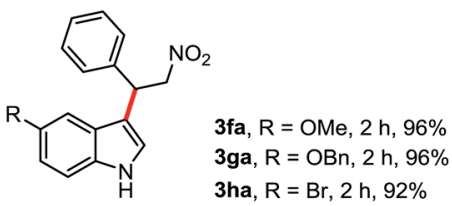

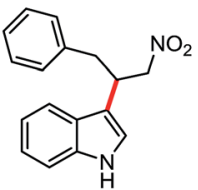

3ao, 8 h, $84 \%$

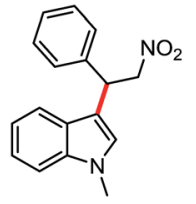

3ba, 2 h, $97 \%$

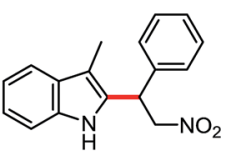

3ea, 2 h, $82 \%$

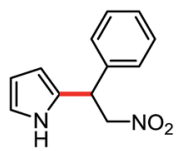

3ia, $2 \mathrm{~h}, 85 \%^{\mathrm{c}}$ (mono/bis: $77 / 23$ )
${ }^{a}$ Conditions: 1a-1h $(0.6 \mathrm{mmol}, 1.2$ equiv.) and $\mathbf{2 a - 2 q}(0.5 \mathrm{mmol})$ was dissolved in HFIP $(0.25 \mathrm{M})$ and stirred at r.t. for a specified period unless otherwise noted. Isolated yields. ${ }^{b}$ Solvent: $\mathrm{CH}_{2} \mathrm{Cl}_{2} / \mathrm{HFIP}(1: 1)$. ${ }^{c}$ Major product is shown. hydrogen bond between HFIP and THF which inhibits the reaction $^{6 \boldsymbol{b}}$ With other fluorinated alcohols, perfluoro-2-methylpropan2-ol (PFTB) was more efficient than the trifluoroethanol (TFE) (entries 10 and 11). In contrast, in EtOH, only traces of product were observed (entry 12). When performed the reaction in the dark had no effect on the yield (entry 13), which suggested HFIP promoted FC alkylation is not a photochemical pathway. ${ }^{12}$

Under the optimized conditions (Table 1, entry 1), the substrate scope and limitation for this FC alkylation between various indoles and $\beta$-nitroalkenes were explored. As shown by the results in Table 2 , all the aryl- $\beta$-nitroalkene analogs tested $(\mathbf{2 a}-\mathbf{2 q})$ reacted with indoles $(\mathbf{1 a - 1 h})$ to produce the corresponding products in excellent yields in HFIP, no matter the presence of substituents with electron withdrawing or electron donating groups in various positions. A variety of functional groups such as methoxy (3ab-3ad), ethoxy (3ae), $N, N$-dimethylamino (3af), halides (3ah-3aj), nitrile (3ak) and nitro (3al) were tolerated. The aliphatic nitroalkenes were successfully transformed into the desired products (3am-3ao) in good yields after $8 \mathrm{~h}$ under the mild conditions. Trans-2-(2-nitrovinyl)-thiophene

Table 3 Scope of FC alkylation between arenes and $\beta$-nitroalkenes ${ }^{a}$

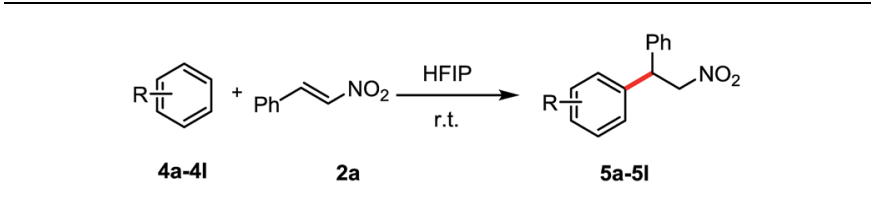

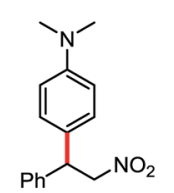

5a, 16 h, $94 \%$

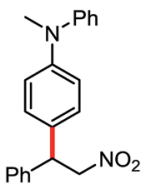

5d, $16 \mathrm{~h}, 78 \%^{b}$ (mono/bis: $84 / 16$ )

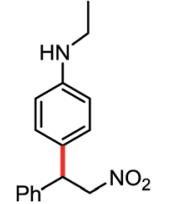

$5 g, 24 \mathrm{~h}, 64 \%^{c}$

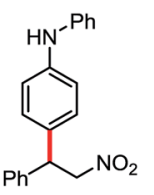

5j, 24 h, $45 \%^{c}$

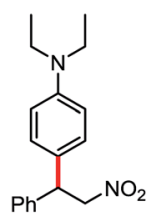

5b, 16 h, $90 \%$<smiles>O=[N+]([O-])CC(c1ccccc1)c1ccc(N(c2ccccc2)c2ccccc2)cc1</smiles>

5e, n.d.

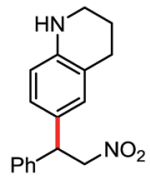

5h, $24 \mathrm{~h}, 65 \%^{c}$

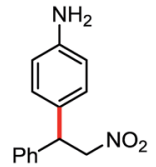

5k, $24 \mathrm{~h}$, trace $^{c}$

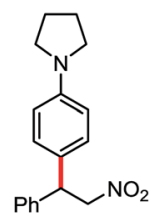

5c, $16 \mathrm{~h}, 94 \%$<smiles>CNc1ccc(C(C[N+](=O)[O-])c2ccccc2)cc1</smiles>

5f, $24 \mathrm{~h}, 67 \%^{\mathrm{C}}$<smiles>O=[N+]([O-])CC(c1ccccc1)c1ccc2c(c1)CCN2</smiles>

5i, 24 h, $61 \%$<smiles>COc1cc(OC)c(C(C[N+](=O)[O-])c2ccccc2)c(OC)c1</smiles>

5I, 16 h, $87 \%$
${ }^{a}$ Conditions: $4 \mathbf{4 a}-\mathbf{4 i}(0.6 \mathrm{mmol}, 1.2$ equiv. $)$ and $2 \mathrm{a}(0.5 \mathrm{mmol})$ was dissolved in HFIP $(0.25 \mathrm{M})$ and stirred at r.t. for a specified period unless otherwise noted. Isolated yields. ${ }^{b}$ Major product is shown. ${ }^{c}$ aza Michael adduct was formed. 
was also applicable in this reaction providing the product 3ap in $92 \%$ yield. Less reactive substrate $N$-tosyl imine showed good reactivity, giving 3aq in $86 \%$ yield after $16 \mathrm{~h}$. This study expands upon our scope of imines with similarly satisfying results. Then various indoles and pyrrole with aryl $\beta$-nitroalkene were tested. Reactions of functionalized indoles $(\mathbf{1} \mathbf{b}-\mathbf{h})$ reacted with $\beta$ nitroalkene smoothly in HFIP to lead to the corresponding products in excellent yields. Treatment of the pyrrole (1i) with $\beta$ nitroalkene afforded a mixture of mono- and bis-substituted products in $77 / 23$ ratio in $85 \%$ yield.

After development of FC alkylation of indoles and pyrrole, we focused on the FC alkylation of arene derivatives. To the best of our knowledge, there are few reports on the FC alkylation of arenes with $\beta$-nitroalkene in the literature. ${ }^{3 f, 13}$

We tested $N, N$-dimethyl aniline with $\beta$-nitroalkene $2 \mathbf{a}$ in HFIP at room temperature. To our delight, the corresponding product 5a was obtained after $16 \mathrm{~h}$ in $94 \%$ yield. Other tertiary anilines such as $N, N$-diethyl aniline (4b), $N$-phenylpyrrolidine (4c) and $N$-methyl- $N$-phenylaniline (4d) were also efficient in these conditions to afford regioselectively only the para-alkylated products. Triphenylamine (4e) showed no reactivity under the same conditions, probably because of the lower electron density at the phenyl ring. Interestingly, the reaction also worked with secondary anilines $(\mathbf{4} \mathbf{f}-\mathbf{4 j})$ in a moderate yield without the presence of the aza Michael product. In contrast to the primary aniline $(\mathbf{4 k})$, the major product was the aza-Michael adduct. Besides, the electron-rich arene, 1,3,5-trimethoxybenzene (4l) reacted with $\beta$-nitroalkene to afford the corresponding alkylated product in good yield (87\%) (Table 3).

Then following to these effective and mild conditions, we investigated the one-pot combination $\mathrm{FC}$ alkylation $/ \mathrm{NO}_{2}$

Table 4 One-pot FC alkylation and reduction of nitro group ${ }^{a}$

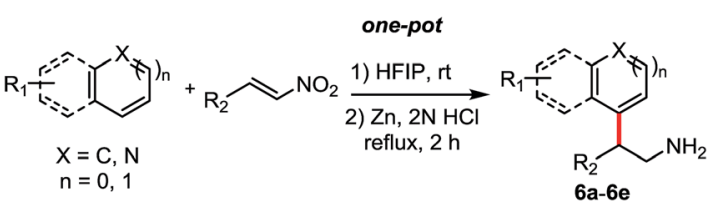

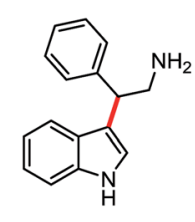

6a, $83 \%$

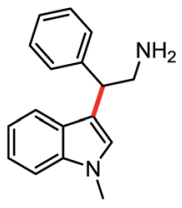

$6 \mathrm{~d}, 84 \%$

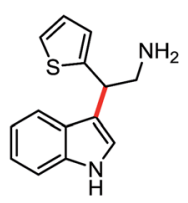

6b, $77 \%$

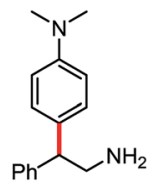

6 e, $81 \%$
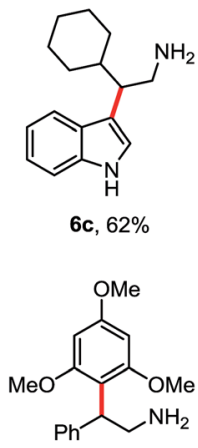

6f, $75 \%$
${ }^{a}$ Conditions: $0.6 \mathrm{mmol}$ of indoles or arenes (1.2 equiv.), $0.5 \mathrm{mmol}$ of $\beta$ nitroalkenes in $2 \mathrm{~mL}$ HFIP for the first step $2.0 \mathrm{mmol}$ of $\mathrm{Zn}$ (4.0 equiv.) and $2.5 \mathrm{~mL} 2 \mathrm{~N} \mathrm{HCl}$ (10 equiv.) were added for the second step. Isolated yields.

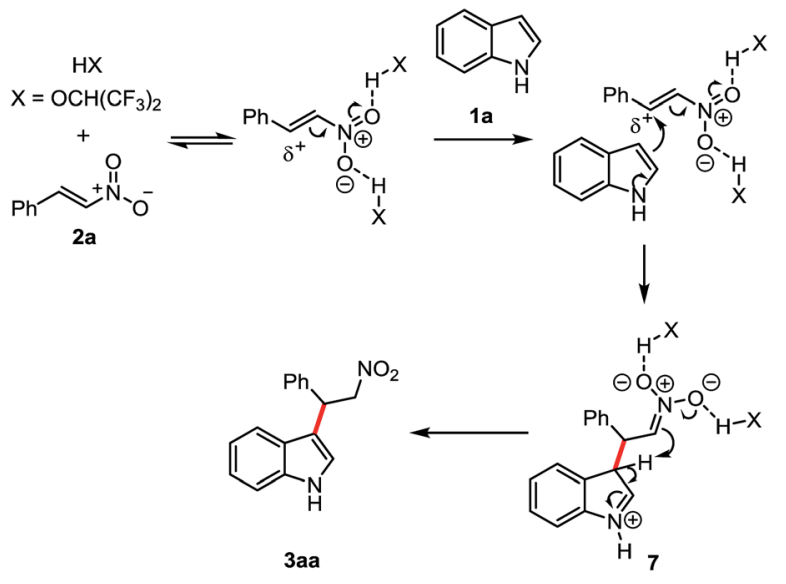

Scheme 2 Proposed mechanism for the FC alkylation.

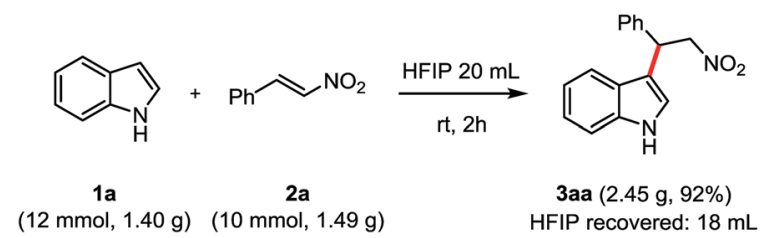

Scheme 3 Gram scale reaction.

reduction. Interestingly, the one-pot synthesis of tryptamines has not been reported previously. In preliminary experiments after completion of the first step, stoichiometric amounts of zinc powder or granular were added. Unfortunately, despite the slight acidity of HFIP, the reduction of the nitro group was not observed at room temperature and at reflux. On the other hand, when $\mathrm{HCl}(2 \mathrm{~N})$ was added, the corresponding tryptamine was formed successfully after $2 \mathrm{~h}$ in reflux. Thus, different reactions have been performed and reported in Table 4 . Indoles and benzene, thiophene and cyclohexane $\beta$-nitroalkenes were tolerated (6a-d). Additionally, reaction with electron-rich arenes such as $N, N$-dimethylaniline, 1,3,5-trimethoxybenzene succeed to lead to the corresponding products $\mathbf{6 e - f}$ in good yields.

Based on the literature ${ }^{6 \boldsymbol{6}, \mathbf{1 0 , 1 4}}$ and our studies, ${ }^{\mathbf{1 1 a , 1 5}}$ a plausible $\mathrm{H}$-bond activation mechanism was proposed in Scheme 2. First HFIP activated the nitro group through hydrogen bond and following by the nucleophilic attack of the indole. The generated intermediate 7 underwent to the subsequent hydrogen transfer to afford the expected product 3aa.

To further explore the synthetic utility of this system, a gramscale reaction was also evaluated (Scheme 3 ). The FC alkylation of $1 \mathrm{a}$ (12 mmol, $1.40 \mathrm{~g})$ with $2 \mathrm{a}(10.0 \mathrm{mmol}, 1.49 \mathrm{~g})$ was performed in $20 \mathrm{~mL}$ HFIP for $2 \mathrm{~h}$. The desired product 3aa was obtained in $92 \%$ yield ( $2.45 \mathrm{~g})$ and $18 \mathrm{~mL}$ of HFIP was recovered after distillation directly from the reaction.

\section{Conclusions}

In conclusion, we have developed an effective and clean FC alkylation between $\beta$-nitroalkenes and arenes in HFIP. The 
desired products formed smoothly in short times at ambient temperature without any additional catalysts or reagents. Further, this methodology can be applied to one-pot synthesis of biologically active tryptamine derivatives. Besides, because of low boiling point (b.p. $=59^{\circ} \mathrm{C}$ ) and low viscosity, HFIP can be easy recovered and reused.

\section{Experimental section}

A general experimental procedure is described as follows:

To a stirred solution of indole $1 \mathrm{a}(70.2 \mathrm{mg}, 0.6 \mathrm{mmol}, 1.2$ equiv.) in HFIP $(2 \mathrm{~mL})$ was added $\beta$-nitroalkene $2 \mathrm{a}(74.5 \mathrm{mg}$, $0.5 \mathrm{mmol}, 1.0$ equiv.) under air. The reaction mixture was stirred at room temperature for $2 \mathrm{~h}$. After, the reaction mixture was evaporated under reduced pressure and the crude product was purified by column chromatography on silica gel using cyclohexane/ethyl acetate (10/1) as the eluent afforded a white solid 3aa (128 mg, 96\% yield).

\section{Conflicts of interest}

The authors declare no competing financial interest.

\section{Acknowledgements}

Central Glass Co. Ltd. is gratefully acknowledged for kindly providing HFIP. R.-J. T. thanks the China Scholarship Council for a doctoral fellowship.

\section{References}

1 (a) C. Friedel and J. M. Crafts, J. Chem. Soc., 1877, 32, 725; (b) M. Bandini, A. Melloni and A. Umani-Ronchi, Angew. Chem., Int. Ed., 2004, 43, 550; (c) T. B. Poulsen and K. A. Jørgensen, Chem. Rev., 2008, 108, 2903; (d) S.-L. You, Q. Cai and M. Zeng, Chem. Soc. Rev., 2009, 38, 2190; (e) V. Terrasson, R. Marcia de Figueiredo and J. M. Campagne, Eur. J. Org. Chem., 2010, 2635; (f) M. Rueping and B. J. Nachtsheim, Beilstein J. Org. Chem., 2010, 6, 6; $(g)$ R. R. Naredla and D. A. Klumpp, Chem. Rev., 2013, 113, 6905.

2 S. Lancianesi, A. Palmieri and M. Petrini, Chem. Rev., 2014, 114, 7108.

3 (a) I. Komoto and S. Kobayashi, Org. Lett., 2002, 4, 1115; (b) Z.-P. Zhan, R.-F. Yang and K. Lang, Tetrahedron Lett., 2005, 46, 3859; (c) H. Firouzabadi, N. Iranpoor and F. Nowrouzi, Chem. Commun., 2005, 789; (d) R. Ballini, R. R. Clemente, A. Palmieri and M. Petrini, Adv. Synth. Catal., 2006, 348, 191; (e) L.-T. An, J.-P. Zou, L.-L. Zhang and Y. Zhang, Tetrahedron Lett., 2007, 48, 4297; $(f)$ N. T. Tran, S. O. Wilson and A. K. Franz, org. lett., 2012, 14, 186; (g) P. M. Habib, V. Kavala, C.-W. Kuo and C.-F. Yao, Tetrahedron Lett., 2008, 49, 7005; (h) L. Liang, Q. Liu, J. Zhang, F. Wang and Y. Yuan, Res. Chem. Intermed., 2012, 39, 1957; (i) M. De Rosa and A. Soriente, Tetrahedron, 2010, 66, 2981.
4 (a) A. Ricci, R. P. Herrera and G. Dessole, Synlett, 2004, 2004, 2374; (b) N. Takenaka, R. S. Sarangthem and S. K. Seerla, org. Lett., 2007, 9, 2819; (c) J. Cai, P. Wu and Y. Wan, Synlett, 2008, 2008, 1193; (d) A. G. Shafer, J. M. Wieting and A. E. Mattson, Org. Lett., 2011, 13, 5228; (e) S. S. So, J. A. Burkett and A. E. Mattson, Org. Lett., 2011, 13, 716; $(f)$ N. T. Tran, S. O. Wilson and A. K. Franz, org. Lett., 2012, 14, 186.

5 (a) M. C. Etter, Z. Urbakzyk-Lipkowska, S. M. Zia-Ebrahimi and T. W. Panunto, J. Am. Chem. Soc., 1990, 112, 8415; (b) C. M. McGuirk, C. L. Stern and C. A. Mirkin, J. Am. Chem. Soc., 2014, 136, 4689.

6 (a) C. Reichardt, Chem. Rev., 1994, 94, 231; (b) A. Berkessel, J. A. Adrio, D. H. ttenhain and J. M. Neudo, J. Am. Chem. Soc., 2006, 128, 8421; $(c)$ A. Börner, I. Shuklov and N. Dubrovina, Synthesis, 2007, 2007, 2925; (d) C. Laurence, J. Legros, P. Nicolet, D. Vuluga, A. Chantzis and D. Jacquemin, J. Phys. Chem. B, 2014, 118, 7594; (e) S. Gennen, M. Alves, R. Mereau, T. Tassaing, B. Gilbert, C. Detrembleur, C. Jerome and B. Grignard, ChemSusChem, 2015, 8, 1845; (f) S. Khaksar, J. Fluorine Chem., 2015, 172, 51; $(g)$ C. Laurence, J. Legros, A. Chantzis, A. Planchat and D. Jacquemin, J. Phys. Chem. B, 2015, 119, 3174.

7 (a) A. Berkessel, J. A. Adrio, D. Huttenhain and J. M. Neudorfl, J. Am. Chem. Soc., 2006, 128, 8421; (b) J. Mars, M. Mezger, A. Wiebe, S. R. Waldvogel and B. Kirchner, ACS Catal., 2017, 7, 1846.

8 G. X. Li and J. Qu, Chem. Commun., 2010, 46, 2653.

9 (a) P. A. Champagne, Y. Benhassine, J. Desroches and J. F. Paquin, Angew Chem Int Ed Engl, 2014, 53, 13835; (b) N. Weisner and M. G. Khaledi, Green Chem., 2016, 18, 681.

10 (a) H. F. Motiwala, R. H. Vekariya and J. Aube, Org. Lett., 2015, 17, 5484; (b) R. H. Vekariya and J. Aube, Org. Lett., 2016, 18, 3534.

11 (a) K. De, J. Legros, B. Crousse and D. Bonnet-Delpon, J. Org. Chem., 2009, 74, 6260; (b) C. Venkateswarlu, P. V. Balaji, K. De, B. Crousse, B. Figadère and J. Legros, J. Fluorine Chem., 2013, 152, 94; (c) A. Fedotova, B. Crousse, I. Chataigner, J. Maddaluno, A. Y. Rulev and J. Legros, J. Org. Chem., 2015, 80, 10375.

12 S. Yadav, M. Srivastava, P. Rai, B. P. Tripathi, A. Mishra, J. Singh and J. Singh, New J. Chem., 2016, 40, 9694.

13 (a) N. Takenaka, R. S. Sarangthem and S. K. Seerla, org. lett., 2007, 9, 2819; (b) A. Z. Halimehjani, M. V. Farvardin, H. P. Zanussi, M. A. Ranjbari and M. Fattahi, J. Mol. Catal. A: Chem., 2014, 381, 21; (c) X.-W. Dong, T. Liu, Y.-Z. Hu, X.-Y. Liu and C.-M. Che, Chem. Commun., 2013, 49, 7681.

14 M. O. Ratnikov, V. V. Tumanov and W. A. Smit, Angew. Chem., Int. Ed., 2008, 47, 9739.

15 (a) K. De, J. Legros, B. Crousse and D. Bonnet-Delpon, Tetrahedron, 2008, 64, 10497; (b) A. Di Salvo, M. David, B. Crousse and D. Bonnet-Delpon, Adv. Synth. Catal., 2006, 348, 118; (c) R.-J. Tang, T. Milcent and B. Crousse, Eur. J. Org. Chem., 2017, 4753; (d) R.-J. Tang, T. Milcent and B. Crousse, J. Org. Chem., 2018, 83, 930. 